Acta Poetica $33 \cdot 2$

JULIO-DICIEMBRE

$2012(61-75)$

\title{
La indianización de Othello
}

\author{
Genoveva Castro y Antonio Castro
}

La película Omkara (2006), dirigida por Vishal Bhardwaj, es una adaptación de la obra de Othello de William Shakespeare. La historia se ubica en la India contemporánea y este ensayo discute las decisiones interpretativas del director. Bhardwaj transfiere exitosamente los valores isabelinos al sur de Asia y logra potenciar el conflicto de Othello de tal manera que el espectador entiende las razones de la tragedia. La cinta contiene los rasgos característicos del cine de Bollywood, pero las nociones fundamentales del texto de Shakespeare también están presentes. Bhardwaj hizo una lectura cuidadosa del texto y reaccionó frente a una serie de elementos que terminaron en decisiones de representación. La narrativa traslada una lectura académica al contexto de una cinta comercial comprensible para el público.

Palabras clave: Omkara, Othello, Bollywood, tragedia, recursos interpretativos.

The film Omkara (2006), directed by Vishal Bhardwaj, is based on the tragedy of Othello by William Shakespeare. The story of this movie is set in contemporary India and the interpretive resources of the film maker are discussed throughout the essay. Bhardwaj successfully transfers the values of the Elizabethan world into contemporary south Asia and it enhances Othello's conflict in a manner such that the spectator apprehends the inherent dangers as the action unfolds. The movie has the characteristic features of Bollywood films, but the basic notions of Shakespeare's text are also present. Bhardwaj undertook a very careful reading of Shakespeare's text reacting to a critical series of events that led to this successful representation which thus rendered a very academic analysis within a popular sphere understandable for the audience. 
Keywords: Omkara, Othello, Bollywood, tragedy, interpretative resources.

Fecha de recepción: 3 de diciembre de 2011

Fecha de aceptación: 12 de abril de 2012 
Genoveva Castro

Universidad de Washington

Antonio Castro

\section{La indianización de Othello}

La película Omkara (2006) fue escrita, dirigida y musicalizada por el realizador indio Vishal Bhardwaj. La historia de la cinta se ubica en la India contemporánea y está basada en la tragedia de Othello de William Shakespeare. La adaptación de Bhardwaj logró resolver exitosamente los anacronismos de la obra de Shakespeare a través de una serie de recursos interpretativos que se discutirán en este ensayo. La tragedia de Othello está enmarcada en la relación padre-hija. La hija, al desobedecer al padre, sella su destino trágico. A pesar de que Désdemona es una mujer virtuosa, tiene una cualidad siniestra. La indianización de Othello es efectiva porque se enfoca en las relaciones familiares al interior de una sociedad sumamente patriarcal y jerárquica.

La shakespearóloga Marjorie Garber señala que los académicos tienden a pensar en raza, clase y género como categorías contemporáneas de análisis. Sin embargo, en la obra de Shakespeare estas categorías están presentes, y son un reflejo de los cambios históricos y sociales de la época ("Othello", 588-589). La India contemporánea también está marcada por importantes negociaciones sociales y de género que se representan en la adaptación de Bhardwaj. El director logró transferir de manera atinada una serie de conflictos del mundo isabelino a la India actual. 
En el sur de Asia, al igual que en el resto del mundo, la lectura y escenificación de las obras de Shakespeare no son una novedad. Durante el dominio inglés y el periodo postcolonial la literatura shakesperiana ha tenido un importante lugar en la educación, el teatro y el cine. La cinta muda Dil Farosh (1927), basada en The Merchant of Venice, fue la primera adaptación cinematográfica de Shakespeare (Trivedi, "Filmi Shakespeare", 230). A esta le siguieron otras que hacen referencias o están basadas en Romeo and Juliet, Antony and Cleopatra, The Comedy of Errors y Richard III, por mencionar algunas. Estas cintas han sido realizadas en diversas lenguas como hindi, urdu y tamil, y utilizan paradigmas del mundo isabelino para hablar de la complejidad cultural del sur de Asia. La más reciente es Karmayogi (2011), dirigida por V.K. Prakash, una adaptación de Hamlet, realizada en malayalam y ubicada en un contexto contemporáneo en Kerala.

Vishal Bhardwaj es originario del estado de Uttar Pradesh (estado en el norte de la India). Comenzó su carrera como músico en la industria cinematográfica de Bombay. Trabajó junto con el célebre director, poeta y músico Gulzar. Años más tarde emprendió sus propios proyectos involucrándose en numerosos aspectos de la producción. Ha dirigido ocho películas, ha colaborado con una decena de guiones y compuesto numerosas canciones para cine y televisión.

La segunda cinta de Bhardwaj, titulada Maqbool (2003), es una adaptación de Macbeth "con el sello distintivo de Bollywood, mezcla el melodrama con atributos típicos de las películas de gánsteres como El Padrino, canciones y bailes [...] Shakespeare se vuelve familiar para su público a través de situaciones contemporáneas" (Dionne y Kapadia, "Introduction", 4). La historia se desarrolla en los bajos mundos de Bombay entre mafiosos y policías corruptos. Bhardwaj considera que "el moderado éxito de Maqbool le permitió cambiar su estatus en la industria cinematográfica" (Kumar, "Literally Pleasing", 1).

Bhardwaj logró por primera vez en Omkara que una cinta suya contara con la participación de varias de las estrellas más famosas del cine de Bollywood como Saif Ali Khan, Kareena Kapoor y Bipasha Basu. Su adaptación de Shakespeare se convirtió en un producto comercial, aunque otros realizadores no dejan de considerar Omkara como cine de arte (Mishra, "No Powerful Roles for Women", 1). La trama de Othello 
es el esqueleto para narrar la historia de una pareja relacionada con las mafias políticas, en un pequeño poblado del estado de Uttar Pradesh, durante la época contemporánea.

La película comienza con la cancelación de la boda de Dolly (Désdemona) y Rajju (Roderigo). La tradicional procesión de la boda hindú está lista, con los invitados presentes, pero la novia huye con Omkara (Othello) porque no quiere celebrar el matrimonio. Rajju le informa al padre de Dolly, Ragunath Mishra (Brabantio) que Omkara (Othello) se llevó a la novia. El padre de Dolly se enfurece porque había arreglado el matrimonio de su hija como manda la tradición.

Omkara es el líder de un grupo de delincuentes que laboran para un poderoso y corrupto político local al que llaman Bhaisaab (Duque de Venecia). Ragunath es un importante abogado en el poblado; también trabaja para Bhaisaab. Por este motivo, el desaguisado con Omkara ocasiona conflictos en su vida profesional. Ragunath busca a Omkara y maldice a la mujer de casta baja que lo parió. Utiliza un lenguaje ofensivo que no es común en las películas de Bollywood.

Omkara es apodado "media casta" por ser el hijo de un hombre de casta alta y una mujer de casta baja. La etnicidad de Othello es fundamental en la tragedia "no solo por quién es él culturalmente, pero también por la manera en que es percibido por los otros y por sí mismo" (Berry, "Othello's Alienation", 46). Los matrimonios arreglados se celebran tradicionalmente entre dos personas de la misma casta. Sin embargo, Dolly se enamora de un hombre que no pertenece a su propia casta y cuya posición social es cuestionada. La unión de Omkara y Dolly viola normas que prevalecen en la época contemporánea. La ambigüedad social de Omkara también contribuye a generar el sentimiento de inseguridad en el personaje. Omkara le expresa al padre de Dolly que el corazón de su hija late por el "media casta". La reacción inmediata de Ragunath es sacar su pistola y apuntarle a Omkara en la cabeza. La tensión se disipa con una llamada desde el teléfono celular de Bhaisaab. Él les solicita que calmen los ánimos y manifiesta su interés en resolver asuntos pendientes.

En una reunión de trabajo, Ragunath llora frente a Bhaisaab y le dice que su hija no pudo ser capaz de huir con un gánster por su propia voluntad. El padre refiere lo insultante que fue la cancelación de la boda, 
así como las recriminaciones sociales de las que es víctima. Su hija es una preciada joya y él no puede entregarla al "media casta". Ragunath incluso dice que no quiere vivir y que la justicia es necesaria. Para resolver el problema, citan a Dolly y escuchan su testimonio sobre lo ocurrido.

Ella refiere la historia de su romance con Omkara y durante un flashback se escucha la canción Naina. La letra introduce varias ideas: "no prestes atención a los ojos, no los escuches / los ojos te engañarán, te van a hipnotizar mientras estés despierto / te van a hipnotizar mientras estés despierto y destruirán tu sueño / los ojos no diferencian entre el bien y el mal; amados y extraños". La canción no es un himno celebratorio del amor entre Dolly y Omkara sino que prefigura la tragedia que va a ocurrir. Las decisiones de Dolly son cuestionadas a través de la letra. La película incluye canciones y bailables porque estos son parte fundamental del cine comercial en la India. La tradición de contar historias con música y baile tiene una raíz antigua y profunda en el sur de Asia.

Dolly se encarga de cuidar a Omkara mientras está herido y se enamora de él. El día que se celebra el compromiso de Dolly y Rajju, ella se quita el anillo que le entrega su prometido. Posteriormente, pone el anillo en una taza de té que le sirve a Omkara. Él descubre el anillo y se sorprende porque no pensaba sostener una relación amorosa con ella. Dolly cuenta la angustia que sintió frente a la decisión de su padre de casarla con Rajju. Finalmente, ella le confiesa su amor a Omkara a través de una carta. Después de escuchar la historia, Bhaisaab sugiere que el asunto se olvide, pero Ragunath no está dispuesto a ignorar la desobediencia de su hija. Cuando el padre se va, la hija se lamenta en silencio.

Ragunath sube a su auto, se atraviesa en el camino de Omkara, abre la ventana y le dice: "No se te olvide que una mujer puede ser un monstruo de dos caras y si fue capaz de engañar a su propio padre, engañará a otros". Esta frase, al igual que en la obra de Shakespeare, se repite varias veces a lo largo de la película. La transgresión de Dolly resulta aún peor que la de Désdemona porque tiene un papel más activo en su romance con Omkara y porque no asiste a la boda planeada por su padre. En Othello, el episodio de la boda con Roderigo no existe. Dés- 
demona es más pasiva, pero se trata de un personaje que tiene fuerza. Garber anota que "de todas las mujeres en la obras de Shakespeare que tienen que decidir entre el padre y el amante (Juliet, Rosalind, Cressida, Isabella y Ophelia), la más directa y menos ambigua es Désdemona" (“Othello", 597). Esta característica de Désdemona se rescata en la adaptación de Bhardwaj.

Bhaisaab es candidato al parlamento, por ello Omkara y sus hombres se encargan de liquidar a uno de sus adversarios políticos. Gracias al excelente trabajo de Omkara, Bhaissab lo designa como su sucesor en la asamblea local. Langda (Iago), cuyo apodo significa "cojo", está casado con la hermana de Omkara. En la cinta, la relación entre ellos debería ser sólida ya que son cuñados. El antiguo puesto de Omkara queda vacío y Langda cree que será el nuevo líder. Langda es un hombre con experiencia, de edad media, que ha trabajado con Omkara durante 15 años. Sin embargo, en el ritual celebrado al interior de un templo hindú, Omkara nombra a Kesu Firangi (Cassio) como su sucesor. Esta situación desata la ira de Langda porque Kesu es un guapo joven que terminó hace poco tiempo la universidad y no tiene trayectoria. Bhaisaab expresa su preocupación por Langda, pero Omkara considera que su lealtad no está en juego. Omkara supone que Kesu puede controlar muy bien a los jóvenes universitarios, lo cual terminará por ser electoralmente rentable.

A pesar de que Langda es interpretado por Saif Ali Khan, uno de los galanes de las comedias románticas de Bollywood, su aspecto resulta poco atractivo, tiene una pierna más corta y da la impresión de ser un hombre mediocre. Sin embargo, al igual que en la obra de Shakespeare, Omkara se equivoca al valorar la capacidad destructiva de Langda. El hombre pequeño y resentido acabará por sellar la tragedia que se inicia en el desencuentro de una hija con su padre. El momento de humillación de Langda está brillantemente representado en la cinta. Bhardwaj trató de incluir en su guión razones que expliquen el comportamiento del villano. La obra de teatro comienza cuando Othello ya escogió a Cassio. Las causas de la conducta de Iago han sido discutidas ampliamente por los académicos y una de las críticas comunes es que "el personaje no tiene motivos, sicología, personalidad o historia que sustenten sus actos" (Calderwood, "The Properties of the Play", 25). Langda 
tiene una relación familiar con Omkara, no puede soportar la traición de un miembro de su familia y es un hombre muy acomplejado.

Omkara lleva a Dolly con su familia. Su hermana Indu (Emilia) está feliz de conocer a la futura esposa de Omkara y hace una serie de comentarios y bromas sobre la tez oscura de él y a la piel clara de Dolly. Indu expresa: "Esta unión se llevó a cabo en el cielo como la leche en una olla con carbón", "como un blanco dulce en la boca de un cuervo", "como el sándalo brillando en la noche más oscura". Termina equiparando a Omkara con el dios Krishna para suavizar a través de una imagen religiosa la diferencia que existe entre ellos: "Su unión es como una flauta en las manos del oscuro Señor". La negritud de Othello es un elemento importante en la obra de Shakespeare aunque las representaciones teatrales y cinematográficas comúnmente tienden a una literalidad que termina por ser anacrónica. La piel morena clara está asociada al ideal de belleza en la India y estos rasgos físicos resaltan aún más el contraste entre Dolly y Omkara.

Langda organiza un plan junto con Rajju para perjudicar a Kesu Ferangi aprovechando el hecho de que el alcohol lo saca de sus cabales. Ferangi significa extranjero y el personaje frecuentemente habla en inglés. En Othello, Cassio es admirado por el moro. No es veneciano sino florentino. Para los ingleses de la época de Shakespeare, "Florencia era un centro de cultura" (Garber, "Othello", 594). El equivalente de Florencia es los Estados Unidos, por lo que Kesu canta canciones norteamericanas. El guerrero, hombre de armas, siente una debilidad por el hombre de mundo, la criatura refinada que entraña todo lo que no es él. Por ello, utilizar a Cassio como depositario de los celos de Othello resulta la decisión más astuta de Iago aunque antes necesita desacreditar al joven.

Los hombres se reúnen para ver a una bailarina llamada Billo (Bianca) que se encarga de entretener a los hombres del pueblo con sus espectáculos. Este es un momento perfecto en la trama para introducir un número musical en el más puro estilo de Bollywood. Una hermosa mujer baila y canta sobre el fuego de la pasión. Este es un motivo típico de la poesía en urdu recobrado frecuentemente en las canciones de Bollywood. Todos beben y bailan junto con ella entusiasmados. La fiesta y los momentos de intoxicación se representan muy frecuentemente 
de esta manera en el cine comercial. Al final de la canción, empieza un violento altercado entre Kesu y Rajju que se termina cuando llaman a Omkara. El plan de Langda resulta un éxito y Omkara se enfurece con Kesu.

Durante la canción Omkara está en su casa con Dolly; le regala un kamarbandh o cinto de metal con piedras preciosas y llamativos acabados (equivalente del célebre pañuelo con las fresas bordadas). Él le dice que las novias de su familia lo han usado durante generaciones; le pide que se lo ponga. Ella se coloca el cinto y seduce a Omkara. La escena erótica es interrumpida por el incidente de Kesu. Nuevamente, Bhardwaj construye un contexto muy claro que explica la importancia del regalo. La obra de teatro no narra el momento en que Othello le obsequia el pañuelo a Désdemona. Ya que el regalo juega un papel tan importante en el desarrollo de la trama, el director optó por su escenificación. Lynda Boose considera que el pañuelo tiene un simbolismo sexual ("Othello's Handkerchief: the Recognizance and Pledge of Love", 366). Bhardwaj logró traducir el pañuelo a un contexto contemporáneo y significativo. Si la joya establece una relación con la sexualidad del personaje femenino, la trayectoria y el cambio de dueño cobran un sentido en la historia.

Langda siembra la semilla de la desconfianza en Omkara cuando ambos ven a Kesu saliendo de la casa de Dolly. Una canción de amor se escucha mientras Omkara y Dolly pasean juntos y sin que lo noten, el cinto se cae al suelo. Indu lo encuentra y lo lleva a su casa. Langda deleitado se lo pone en la cabeza, incluyéndolo en su propio juego erótico. La oposición entre la dulzura de Dolly y la maldad de Langda es muy marcada en esta escena. Los diálogos hacen referencias a la naturaleza animal de Langda. En la obra "más de la mitad de las imágenes de animales son de Iago y todas ellas son despectivas o repelentes" (Bradby, Shakespeare Criticism, 42). En este sentido, la película Omkara reproduce el espíritu de la obra de Shakespeare.

Omkara y Dolly planean su boda, pero tienen que esperar el día auspicioso indicado por el astrólogo. Kesu impulsado por Langda le pide a Dolly que lo ayude a convencer a Omkara que lo perdone. Dolly y Kesu son más jóvenes que Omkara; fueron compañeros en la universidad lo 
que explica su buena relación. Dolly trata de abogar en favor de Kesu y sus comentarios comienzan a enloquecer a Omkara.

Un atentado en contra de Bhaisaab obliga a Omkara y sus hombres a planear una venganza. Kesu es marginado de todas las actividades de la banda de criminales, con lo que se siente decepcionado. Para aliviar un poco el malestar de Kesu, Langda le da el cinto para que se lo obsequie a Billo. Ella recibe el regalo con gusto y se coloca el cinto en un apasionado baile, que los borrachos aplauden a rabiar. Simultáneamente, ocurren ataques en contra de los adversarios políticos de Bhaissab. El número musical funciona para mostrar lo que sucedió con el regalo de Omkara. "El pañuelo es una señal de amor íntimo y se vuelve un espectáculo público" (Garber, "Othello", 611). La canción de Billo cumple una doble función. Por un lado, vuelve público el descuido de Dolly y por otro, sigue las fórmulas indispensables del cine comercial indio.

El personaje de Bianca se convierte en la cortesana prototípica del cine de Bollywood. "La figura de la cortesana como bailarina es una poderosa representación de sexualidad" (Clark, Kathak in Hindi Films, 129). Bianca juega un papel secundario en la obra de Shakespeare, pero Billo aprovecha un espacio destacado en el imaginario literario y cinematográfico del sur de Asia. Las escenas de mujeres que bailan y seducen a los hombres con sus encantos son sumamente comunes. Este es otro ejemplo del proceso de indianización de la obra de Shakespeare.

Omkara le pide a Dolly que le muestre el cinto, mas ella no lo encuentra. Él la recrimina diciendo que perdió en tres días una reliquia que ha permanecido en su familia por generaciones. Omkara le pregunta a quién le regaló el cinto, pero ella explica que no tiene a nadie en el mundo. Ella abandonó a su familia para quedarse con Omkara. Nuevamente, se escucha una canción que introduce la idea del fuego en el corazón, en esta ocasión debido al dolor. Las canciones en el cine de Bollywood suelen expresar las emociones y la vida interior de los personajes en momentos fundamentales de la trama. En este sentido, Omkara no es una excepción.

Langda continúa con su plan de enloquecer a Omkara de celos y miente proporcionado detalles falsos sobre los dichos de Kesu. El guerrero exige pruebas de la infidelidad de su mujer. "Las pruebas oculares" de la infidelidad de Dolly recuerdan la primera canción de la pe- 
lícula en la que se sugiere que los ojos pueden engañar. Omkara afirma: "Al mirar los ojos de Dolly, todo tu Ramayana me parece falso". Se trata de una clara referencia a la castidad de Sita. En el poema épico, Sita es cuestionada porque habitó en la casa de otro hombre después de ser raptada. A pesar de su inocencia, ella tiene que pasar una ordalía de fuego que certifique su pureza. Más adelante en este texto, las habladurías de la gente provocan que su fidelidad se ponga en entredicho una segunda vez. La historia del Ramayana es una de las más populares en el sur de Asia. La transferencia al personaje de Sita permite que los espectadores entiendan el problema en términos muy conocidos. Con el comentario de Omkara, Dolly se convierte en uno de los paradigmas prototípicos de las mujeres hindúes. A pesar de que es virtuosa, existen acusaciones sobre su castidad.

Una serie de confusiones y malos entendidos provocan que Billo regrese el cinto enfurecida. Bhardwaj "hace un uso inteligente de la tecnología del teléfono celular en distintas partes de la película" (Trivedi, "Filmi Shakespeare", 243); al final es uno de los medios de Langda para desatar el clímax de la tragedia. Omkara escucha la disputa en la que el cinto vuelve a manos de Kesu y sus sospechas se reafirman.

Los preparativos de la boda van a llegar a su fin cuando un pájaro arroja un objeto muy cerca de Dolly, lo cual es considerado como un signo ominoso. La situación resulta un presagio de su destino trágico. Indu habla con Omkara para cuestionarlo por su comportamiento agresivo y desconfianza hacia Dolly. Él contesta que las palabras del padre de su novia resuenan en sus oídos. Indu declara la facilidad con la que se acusa a las mujeres de ser infieles y aboga por Dolly. El día de la boda, Langda le dispara a Kesu y Omkara acusa a Dolly de infidelidad y la estrangula. Poco después, Indu aparece en la habitación, se da cuenta del daño causado por Langda y lo mata. Omkara se percata de su equivocación al dudar de su esposa y se suicida. La boda es un componente muy importante en las películas de Bollywood: Omkara empieza y termina con ese ritual interrumpido.

La tragedia de Othello ha sido criticada porque ciertos incidentes de la obra parecen muy triviales. Thomas Rhymer en su discusión de la obra señala que existe "demasiado énfasis, pasión y repetición sobre un pañuelo. Esta obra debería de llamarse La Tragedia del pañuelo" 
(A Short view of Tragedy, 139). Se ha gastado una gran cantidad de tinta sobre el significado del pañuelo. El artículo de Boose discute si el objeto es trivial y si la locura de Othello le da una importancia desproporcionada ("Othello's Handkerchief: the Recognizance and Pledge of Love", 360). Los estudiosos de la materia sugieren que las fresas son emblemáticas de la "sangre virginal" (362), que los diseños de fresas eran comunes en la época y que estaban asociados a las "representaciones religiosas de la vírgenes" (Ross, "The Meaning of Strawberries in Shakespeare", 235), pero tienen una doble connotación de "amor carnal y virginidad" (231). Boose señala que el pañuelo es una "reducción visual de las sábanas matrimoniales manchadas" ("Othello's Handkerchief: the Recognizance and Pledge of Love", 366).

En las versiones cinematográficas de Othello de Orson Welles (1952) y de Oliver Parker (1995), el pañuelo resulta sumamente anacrónico, con lo que la obsesión de Othello por el objeto no parece tener sentido. Aunque originalmente el pañuelo estaba cargado de significado, en la actualidad su simbolismo está perdido. Bhardwaj resuelve de manera inteligente y creativa el problema introduciendo en la trama una joya de familia que devuelve la importancia erótica del objeto. El espectador no tiene que ser un experto en la obra de Shakespeare para entenderlo.

Desoír al padre en el mundo occidental contemporáneo no parece una buena causa para una tragedia. Sin embargo, en numerosas películas de Bollywood la tensión entre la tradición y la modernidad, los matrimonios arreglados y por amor, la lucha entre los deseos individuales y las normas del núcleo familiar se representan constantemente. Este tipo de conflictos afecta la sensibilidad de muchas personas en el sur de Asia. Othello ha sido etiquetada como una "tragedia doméstica" (Garber, "Othello", 603). En la película de Bhardwaj, Omkara y Langda son cuñados y "las relaciones familiares juegan un papel significativo" (Gruss, "Shakespeare in Bollywood? Vishal Bhardwaj's Omkara", 230). La domesticidad de Othello tiene un paralelo con temas recurrentes en el cine comercial de la India y no es una casualidad que el director de Omkara haya optado por la adaptación de esta obra.

Las decisiones de Bhardwaj con respecto a sus personajes femeninos llaman especialmente la atención. Aunque la obra está enmarcada en un mundo patriarcal desde su planteamiento hasta el final, Dolly cuestiona 
los límites de ese mundo en el que los hombres mandan. Ya señalamos que su personaje es más atrevido que el equivalente shakesperiano: ella seduce a su futuro marido, se rehúsa a aceptar el matrimonio designado por su padre y, a diferencia de Omkara, nunca titubea. Sin duda, Dolly resulta el personaje más subversivo de Omkara y nos obliga a replantear nuestra concepción de Desdémona, con tanta frecuencia representada como un paradigma de ingenuidad inofensiva. Por otro lado, Indu asesina a su marido cuando se da cuenta que Dolly fue culpada injustamente. En la obra de Shakespeare, Emilia desaprueba las acciones de Iago: Bhardwaj la vuelve notoriamente más audaz. Por último, el personaje de Billo es un despliegue de sensualidad, un prototipo con una larga historia en la literatura y en el cine de la India. Bhardwaj convirtió a Bianca en una bailarina y justificó sus apariciones musicales que mezclan el folclor local, la música clásica y la orquestación moderna.

Como señala Loomba, la crítica feminista de Othello puede centrarse en el destino de los personajes y los castigos que expone el hostil orden patriarcal que reprime a las mujeres, pero la resistencia de Désdemona a ese orden también puede evaluarse ("The Color of Patriarchy", 2425). En la película, las mujeres son calificadas como monstruos o "seres anormales" de dos caras y capaces de engañar. Ciertamente, el destino de Dolly es terrible. Sin embargo, existe una crítica muy fuerte al mundo patriarcal y un desencuentro de valores. Los juicios del padre de Dolly y de Omkara están equivocados. Dolly cuestiona el status quo del mundo al que pertenece. Aunque en menor medida, también se critican los valores ligados a la etnicidad, casta y jerarquía. El director muestra abiertamente también la corruptela de la clase política.

Evidentemente Bhardwaj no hizo una lectura literal de la obra, el lenguaje está muy alejado de Shakespeare, pero estudió con detalle los componentes más importantes del drama. Dos de las críticas fundamentales de la obra son: la falta de claridad de los motivos de Iago y el problemático pañuelo. Cuando la obra comienza, Cassio ya ha sido elegido y el pañuelo lo tiene Désdemona. Bhardwaj escenifica los antecedentes y agrega un par de escenas para que esos sucesos de la trama cobren sentido. En una de las escenas podemos ver la decepción de Langda porque no fue elegido como el sucesor. Más adelante, el juego erótico en el que Omkara le entrega a Dolly la joya de su familia. 
El mérito de Omkara consiste en que logra potenciar el conflicto de Othello de tal manera que el espectador entiende por qué son peligrosos los actos que están ocurriendo. Lector cuidadosísimo del texto de Shakespeare, Bhardwaj reacciona frente a los hechos que le parecen anacrónicos y los enmarca en un contexto contemporáneo. Su película logra trasladar una lectura de profundidad académica a un ámbito popular y emocional.

\section{REFERENCIAS}

Berry, Edward, “Othello's Alienation", en Othello: Bloom's Modern Critical Interpretations New Edition, Harold Bloom (ed.), New York, Chelsea House, 2010, 43-61.

Boose, Lynda E., "Othello's Handkerchief: the Recognizance and Pledge of Love", en English Literary Renaissance, V, 1975, 360-374.

Bradby, Anne, Shakespeare Criticism [1936], London, Oxford University Press, 1936.

CAlderwood, James, "The Properties of the Play", en Othello: Bloom's Modern Critical Interpretations New Edition, Harold Bloom (ed.), New York, Chelsea House, 2010, 21-43.

Clark, Lori, Kathak in Hindi Films, tesis de maestría, American University, 1998.

Dionne, Craig y Parmita KAPADIA, "Introduction", en Native Shakespeares: Indigenous Appropriations on a Global Stage, Craig Dionne y Parmita Kapadia (eds.), Aldershot, Ashgate, 2008, 1-19.

Garber, Marjorie, "Othello", en Shakespeare After All, Marjorie Garber (ed.), New York, Anchor Books, 2004, 588-617.

Gruss, Susanne, "Shakespeare in Bollywood? Vishal Bhardwaj's Omkara", en Semiotic Encounters: Text, Image and Trans-Nation, Sarah Säckel, Walter Göbel y Noha Hamdy (eds.), Amsterdam / New York, Rodopi, 2009, 223238.

Kumar, Anuj, "Literally Pleasing”, en The Hindu, May 11 2007, <http://www. hindu.com/fr/2007/05/11/stories/2007051150870100.htm $>$ [fecha de consulta: enero de 2012].

Loomba, Ania, "The Color of Patriarchy: Critical Difference, Cultural Difference, and Renaissance Drama", en Women, Race and Writing in the Early Modern Period, Margo Hendricks y Patricia Parker (eds.), London, Routledge, 1994, 17-34. 
Mishra, Sudhir, "No Powerful Roles for Women", en The Hindu, December 29, $2007<\mathrm{http}$ //www.thehindu.com/todays-paper/tp-features/tp-metroplus/article2280881.ece> [fecha de consulta: enero de 2012].

Ross, Lawrence J., "The Meaning of Strawberries in Shakespeare", en Studies in the Renaissance, vol. VII, 1960, 225-240.

Rhymer, Thomas, A Short View of Tragedy [1693], Yorkshire, Scholar Press, 1970.

Trivedi, Poonam, "Filmi Shakespeare", en Narratives of Indian Cinema, Manju Jain (ed.), Delhi, Primus Books, 2009, 229-248. 
